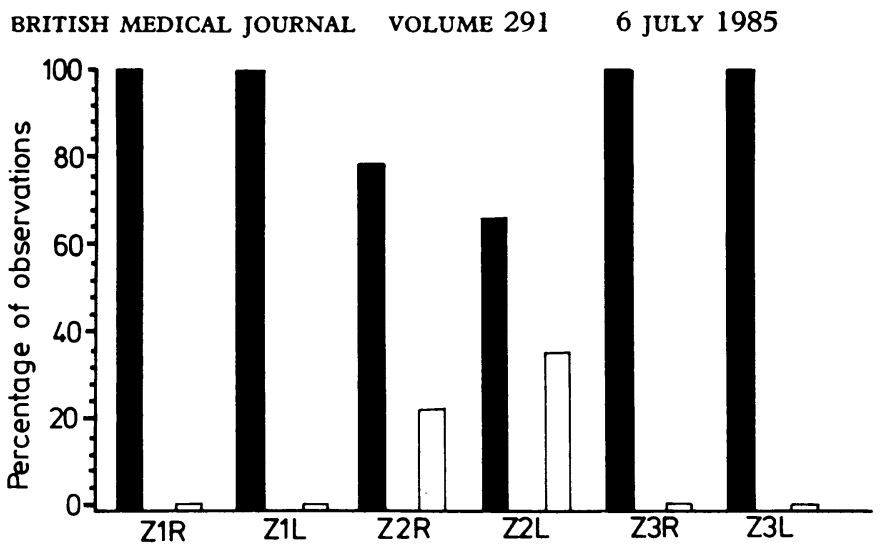

FIG 5-Interexaminer agreements (solid columns) and disagreements (open columns). Results presented as percentage of total responses for each zone (Z) for all 23 dogs. (Thoracic dorsum right and left.)

disagreements showed significant bias. There was good evidence of interexaminer agreement, since bias was shown in only seven of 13 disagreements and significant interexaminer disagreements occurred in only 13 out of a total of 138 sites ( 3 zones (right and left) $\times 23$ ) in the 23 animals examined.

We have established that somatic changes in the thoracic dorsum can be detected by routine palpation of soft tissue in patients with acute myocardial infarction. These observations may provide the physician with a simple bedside manoeuvre to aid in diagnosing an acute myocardial infarction or predicting an impending myocardial infarction. Further investigation is required to define the anatomy of the sympathetic reflex arc and also to delineate palpable changes found in cardiovascular diseases other than acute myocardial infarction.
We are grateful to the nursing staff in the step down unit of the intensive care unit for their cooperation; Dr Hyman Menduke, Jefferson Medical College, for advice on statistical analyses; Ms Maria V Arbizo for coordinating the technical aspects of the study and designing computer programs; Ms Wanda L Young for computer generated graphics; Mr Dennis A DeBias, Ms Dorothy $\mathrm{H}$ Driscoll, and $\mathrm{Dr}$ Jon Oline for reviewing the manuscript; the director and residents of Overmont House for their participation; Mr Paul Harm for photography; and Ms Christine M Cirillo for typing the manuscript.

The study was supported by grants from the American Osteopathic Association Bureau of Research (grant No 81-10-036) and the Philadelphia College of Osteopathic Medicine.

\section{References}

1 Denslow JS. Pathophysiologic evidence for the osteopathic lesion. In: Goldstein MM, ed. The research status of spinal manipulative therapy. Bethesda, Md Eble JN. Somatic manifestations of experimental visceral disturbances. fournal

of Osteopathy 1958;65:13-6.
Rumney IC. The relevance of somatic dysfunction. 7 Am Osteopath Assoc 1975; 74:723-5.

4 Hitchcock ME. Myocardial considerations in the thoracic area. Osteopathic Medicine 1978;3:85-94.

Tilley RM. The somatic component in heart disease. Osteopathic Annals 1974 2:30-7

DeBias DA, Greene CH, Heilig D, Nicholas AS, Harrer WV. A somatic component to experimental myocardial infarction. Physiologist 1980;23:118.

ponent to experimental myocardial infarction. I Am Osteopath Assoc $1982 ; \mathbf{2}$ 139.
pole .

Cole WV. A reflex basis for osteopathic medicine. I Am Osteopath Assoc 1963 63: $343-50$.

Cathie AG. Some anatomicophysiologic aspects of vascular and visceral disturbances with special references to cardiac disease. Yearbook of the Academy of Applied Osteopathy 1965:92-7.

10 Koch RS. The spinal component in heart disease. Yearbook of the Academy of Applied Osteopathy 1957:67-72.

Patriquin DA. Osteopathic management of coronary disease. Yearbook of the

54-63.

(Accepted 25 March 1985)

\title{
Deaths from rhesus haemolytic disease in England and Wales in 1982 and 1983
}

\author{
CYRIL A CLARKE, P L MOLLISON, A G W WHITFIELD
}

\begin{abstract}
Examination of death certificates and the clinical notes of the patients concerned showed that the number of deaths from rhesus (D) haemolytic disease in England and Wales was 44 and 34 during 1982 and 1983, respectively, a substantial decrease from the figure of 106 for 1977. Of the 78 women whose infants died in 1982 and 1983, 49 had not received anti-Rh immunoglobulin
\end{abstract}

Royal College of Physicians Research Unit, London NW1 4LE CYRIL A CLARKE, FRCP, FRS, director

A G W WHITFIELD, MD, FRCP, assistant director

North London Blood Transfusion Centre, Edgware, Middlesex P L MOLLISON, FRCP, FRS, honorary consultant

Correspondence and requests for reprints to: Sir Cyril Clarke. after previous pregnancies with $R$ h positive infants; most of these deaths would presumably have been prevented had postnatal anti-Rh immunoglobulin been given. In 13 women anti-D was detected during, or immediately after, a first pregnancy, and in 15 women rhesus immunisation developed despite administration of anti-Rh immunoglobulin postnatally. One or two apparent failures of treatment may have been due to underdosage, but it must be concluded that about one third of the deaths in 1982 and 1983 could have been prevented only by giving anti-Rh immunoglobulin antenatally as well as postnatally.

\section{Introduction}

Since 1977 deaths from rhesus haemolytic disease in England and Wales have been analysed with the particular intentions of discovering the circumstances in which each mother became immunised and assessing the accuracy of certification of death. Results for 1977 to 1981 inclusive have been reported previously. ${ }^{1-5}$ 


\section{Methods}

Copies of death certificates for all infants reported as having died from haemolytic disease were obtained from the Office of Population Censuses and Surveys. We wrote to the obstetricians concerned and in every case obtained either the original notes on brief loan or a summary. The following changes in analysing the information were made from the method used in the earlier reports ${ }^{1-5}$ :

(1) Stillbirths and deaths occurring in liveborn infants were considered together because a distinction between them seemed artificial. Many infants who had little or no chance of surviving in utero till term were born alive prematurely as a result of obstetric interference-for example, caesarean section-only to die within a few hours.

(2) The term rhesus haemolytic disease was modified to rhesus (D) haemolytic disease. It is hoped that ICD category 7730 will be changed from rhesus haemolytic disease to rhesus (D) haemolytic disease so that deaths due to haemolytic disease caused by anti-c, anti-E, etc will be transferred to category 7732 , which already includes deaths due to anti- $K$, etc. Category 7730 would then be restricted to deaths that are preventable by anti-Rh (D) immunoglobulin.

(3) Women who might have been immunised as a consequence of an abortion were not considered separately from women immunised by one or more full term pregnancies. In the two years there were nine cases in which immunisation might have been caused by an abortion, but in four of these it might also have been caused by one or more preceding full term pregnancies after which no anti-Rh immunoglobulin had been given. Thus there were only five cases in which abortion (spontaneous or induced) probably initiated rhesus immunisation.

(4) Women who had not been treated with anti-Rh immunoglobulin after one or more previous deliveries and who had become immunised were subdivided into those who had had at least one delivery before 1970 and those in whom all deliveries occurred from 1970 onwards. This classification was only a minor change from the previous one, whereby such women were subdivided into those immunised before and those immunised after anti-Rh immunoglobulin became available. This change was made because in some cases a woman had become immunised after having a pregnancy in 1970 or later in a country where anti-Rh immunoglobulin may not have been available.

\section{Results}

The table presents an analysis of deaths reported to be due to haemolytic disease (ICD categories 7730 and 7732) in 1982 and 1983. The number of deaths from rhesus haemolytic disease was estimated to be 44 and 34 in 1982 and 1983, respectively. According to the Office of Population Censuses and Surveys, the total number of births (live born and stillborn) for these years was roughly 630000 and 633000 so that the overall mortality for 1982 and 1983 was $7 \cdot 0$ and 5.4/100 000 births, respectively.

Deaths in infants (liveborn and stillborn) reported as due to haemolytic disease in England and Wales in 1982 and 1983

\begin{tabular}{|c|c|c|c|c|}
\hline \multirow{2}{*}{$\begin{array}{l}\text { Previous } \\
\text { category* }\end{array}$} & \multirow{2}{*}{$\begin{array}{l}\text { New } \\
\text { category }\end{array}$} & \multirow[b]{2}{*}{ Description } & \multicolumn{2}{|c|}{ Year } \\
\hline & & & 1982 & 1983 \\
\hline 1 and 2 & I & $\begin{array}{l}\text { No postnatal anti-Rh immunoglobulin after one } \\
\text { or more previous deliveries: } \\
\text { (a) At least one of which occurred before } \\
1970\end{array}$ & 17 & \\
\hline $\begin{array}{l}6 \\
3\end{array}$ & II & $\begin{array}{l}\text { (b) Occurring from } 1970 \text { onwards } \\
\text { Anti-D detected during, or not later than seven } \\
\text { days after. first delivery }\end{array}$ & 16 & 12 \\
\hline 5 & III & Immunised despite postnatal anti-Rh after & 5 & 8 \\
\hline 7 & IV & $\begin{array}{l}\text { previous pregnancies } \\
\text { Immunised by blood transfusion }\end{array}$ & 6 & $\begin{array}{l}9 \\
1\end{array}$ \\
\hline \multicolumn{3}{|c|}{ Total deaths from rhesus (D) haemolytic disease ${ }^{+}$} & 44 & 34 \\
\hline $\begin{array}{l}4 \\
9\end{array}$ & $\begin{array}{l}\mathrm{V} \\
\mathrm{VI}\end{array}$ & $\begin{array}{l}\text { Non-rhesus (D) haemolytic disease } \\
\text { Not haemolytic disease }\end{array}$ & $\begin{array}{r}4 \\
19\end{array}$ & $\begin{array}{r}4 \\
17\end{array}$ \\
\hline Total & & & 67 & 55 \\
\hline
\end{tabular}

* Of the present cases, none fell into category 8 (rhesus (D) death but unscorable for category). +Our estimates for total deaths from rhesus (D) haemolytic disease in previous
years: 1977,$106 ; 1978,90 ; 1979,87 ; 1980,72 ;$ and 1981,41 .
Of the 78 patients adjudged by us to have died from rhesus (D) haemolytic disease in the two years, 49 were women who had not been treated with anti-Rh immunoglobulin after one or more previous pregnancies with a $\mathrm{Rh}$ positive infant. Of these, 21 had been immunised by pregnancies occurring before 1970, when anti-Rh immunoglobulin was not generally available. Of the 28 women immunised from 1970 onwards, six had had their immunising pregnancy outside Britain in a country where anti-Rh immunoglobulin was not readily available; the remaining 22 women had had their babies in England or Wales and were not given anti-Rh immunoglobulin even though it was freely available from regional blood transfusion centres. Thirteen women formed anti-D during a first pregnancy or within seven days after their first delivery, and 15 became immunised despite being given anti- $\mathrm{Rh}$ immunoglobulin postnatally. One was immunised by a blood transfusion.

Eighto infants died of haemolytic disease due to antibodies other than anti-D (seven due to anti-c with or without anti-E and one due to anti-K), and 36 were judged not to have died of haemolytic disease in any form; a common error was to certify the death of an infant as being due to rhesus haemolytic disease simply because its mother was $\mathrm{Rh}$ (D) negative even though anti-D was not detected.

Of the deaths from rhesus (D) haemolytic disease in 1982 and 1983,38 were of liveborn infants and 40 of stillbirths. Maturity was known in 31 and 38 cases, respectively, and was similar in the two groups-for example, about $30 \%$ of deaths (nine out of 31 live births and 12 out of 38 stillbirths) were in infants aged 31-34 weeks and about $45 \%$ (14 out of 31 live births and 17 out of 38 stillbirths) were in infants aged 28-30 weeks.

The premature birth of liveborn infants was usually the result of elective caesarean section but was sometimes provoked by intrauterine transfusion or other obstetric manoeuvres. Three live births occurred before the 28 th week of pregnancy, one at the 25 th week, and two at the 27 th week.

\section{Discussion}

The results were analysed to find differences between those obtained in 1982 and in 1983 and between those obtained in 1982 and 1983 and those obtained in 1977-81.

Total deaths-During 1977-81 the total number of deaths from rhesus (D) haemolytic disease fell progressively (table). Although the total was marginally higher in 1982 than in 1981, the downward progress was resumed in 1983.

Category Ia-The most striking difference between 1982 and 1983 was the steep fall in the number of infants born to mothers immunised by a pregnancy occurring before 1970 . The number of infants in this category decreased progressively from 1977 onwards (as expected) with 49 such deaths in 1977 but only four in 1983.

Category $I b$ - The decline in the number of women immunised by a pregnancy occurring from 1970 onwards, after which no anti-Rh immunoglobulin was given, seems disappointing, the number being 32 in 1977 and 16 and 12 in 1982 and 1983, respectively. In 1983, however, as many as six of the 12 women had been immunised by pregnancies when they were living outside Britain, so that within Britain at least progress is being made in ensuring that anti-Rh immunoglobulin is given when indicated.

Categories II and III-Cases in categories II and III were those in which anti-D was formed during a first pregnancy (II) or in which a woman became immunised despite having been given anti-Rh immunoglobulin postnatally after all previous deliveries (III). In category III it is impossible to know whether primary immunisation occurred after an earlier pregnancy despite the administration of anti-Rh immunoglobulin or during a subsequent pregnancy. In practice, cases in both these categories might have been prevented if anti-Rh immunoglobulin had been given antenatally. During 1977-83 the total numbers in these two categories changed little, the numbers each year being $21,18,22,17,15,11$, and 17 ; in 1983 they accounted for about half the total deaths from haemolytic disease due to anti-D. The fact that the numbers of cases in categories II and III did not fall substantially between 1977 and 1983 suggests that improved treatment of haemolytic 
disease, as contrasted with improved prevention, did not play a major part in the overall decline in mortality from the disease during this period.

Category IV-Only one mother had been immunised by blood transfusion, bringing the total for 1977-83 to five.

Category V-As expected, the number of deaths from haemolytic disease due to antibodies other than anti-D varied little during 1977-83 being four, three, three, three, two, three, and four. Almost all were due to anti-c.

Category VI-The number of infants entered wrongly (in our opinion) as dying of haemolytic disease remained substantial. Although the number fell from 45 and 49 in 1977 and 1978 to 21 and 28 in 1979 and 1980, perhaps partly as a result of our earlier reports, the numbers scarcely changed subsequently, being 14, 19, and 17 in 1981, 1982, and 1983, respectively.

Category I ( $a$ and b) included five cases in which a woman had been treated with anti-Rh immunoglobulin after the immediately preceding pregnancy but had not been treated with it after one or more earlier pregnancies. It is debatable whether these five cases should rather have been included in category III.

Deaths of liveborn infants and stillbirths were considered together because obstetric practice plays a substantial part in determining whether a severely affected infant is born alive prematurely or dies in utero. Our results show that over $40^{\circ}{ }_{0}$ of the deaths of liveborn infants and of the stillbirths occurred at 28-30 weeks of gestation. Three deaths occurred in infants born alive before the 28 th week of gestation. It is, of course, an anomaly that these deaths are registrable whereas stillbirths occurring before the 28 th week are not, a fact that must lead to an underestimate of the overall mortality of fetuses from rhesus haemolytic disease.

The number of deaths due, indirectly, to the failure to give
anti-Rh immunoglobulin to the mother after previous deliveries continues to diminish. Our data, however, indicate that even if anti-Rh immunoglobulin were given postnatally to all mothers who were $R h(D)$ negative there would still be between 11 and 22 deaths from rhesus haemolytic disease each year in England and Wales (based on the figures for 1977-83). These deaths occur in women who develop anti-D by the end of a first pregnancy or in a second or subsequent pregnancy despite having received anti-Rh immunoglobulin postnatally. Evidence suggests that in a high proportion of such cases rhesus immunisation can be prevented by giving anti-Rh immunoglobulin antenatally. ${ }^{6}$ " Clearly, the virtual elimination of rhesus haemolytic disease can be achieved only by giving anti-Rh immunoglobulin antenatally as well as postnatally.

We thank the many obstetricians who made this study possible and $\operatorname{Dr} M \mathrm{R}$ Alderson, who supplied the death certificates, $\mathrm{Mr} \mathrm{M}$ McDowall, and Mrs J I Jordan for discussions.

\section{References}

1 Clarke CA, Whitfield AGW. Deaths from rhesus haemolytic disease in England and Wales in 1977: accuracy of records and assessment of anti-D prophylaxis. Br Med f 1979; ; :1665-9.

2 Clarke CA, Whitfield AGW. Rhesus immunisation during pregnancy: the case for antenatal anti-D. Br Med f 1980;280:903-4

Clarke CA, Whitfield AGW. Deaths from rhesus haemolytic disease in England and $W$ ales in 1978: accuracy of records and assessment of anti-D prophylaxis. $781-2$.

4 Clarke CA. Whitfield AGW. Deaths from rhesus haemolytic disease in England and Wales in 1979. Fournal of Obstetrics and Gynaecology $1983 ; 3: 144-51$.

Clarke CA, Whitfield AGW. Deaths from rhesus haemolytic disease in England and $W$ ales during 1980 and 1981 and a comparison with earlier years. Fournal of Obstetrics and Gynaecology 1984;4:218-22.

6 Bowman JM, Pollack J. Rh immunization in Manitoba: progress in prevention and management. Can Med Assoc $\mathcal{F} 1983 ; 129: 343-5$

7 Tovey LAD, Townley A, Stevenson BJ, Taverner J. The Yorkshire antenatal anti-D immunoglobulin trial in primigravidae. Lancet 1983;ii:244-6.

(Accepted 4 April 1985)

\begin{abstract}
To see whether continuous intravenous infusion of opiates provides more effective postoperative relief of pain than conventional intramuscular injection these regimens were compared in a prospective double blind trial. Thirty patients undergoing elective cholecystectomy were allocated randomly to receive an infusion of morphine or an infusion of placebo (control group) for 24 hours. Both groups were allowed supplementary morphine
\end{abstract}

Royal Alexandra Infirmary, Paisley PA2 6LX

HUW MARSHALL, MB, CHB, registrar in anaesthetics

Western Infirmary, Glasgow G11 6NT

COLIN PORTEOUS, $M B$, FRCS, lecturer in surgery

IAN MCMILLAN, MB, FRCS, lecturer in surgery

STLART G MACPHERSON, MB, FRCS, senior lecturer in surgery

WALTER S NIMMO, MD, FFARCS, senior lecturer in anaesthetics

Correspondence and requests for reprints to: Mr C Porteous. boluses as requested. During the first 48 hours after operation the degree of pain was almost identical between the groups. Surprisingly, the group that was given the infusion of morphine received as much supplementary morphine as the control group during the first 24 hours and appreciatly more during the 24 hours after the infusion had been withdrawn. Nausea and vomiting were more prevalent among the patients given the infusion of morphine.

These results suggest that continuous infusion of morphine may be an inferior regimen to intermittent bolus administration in the relief of postoperative pain. This may be explained by the development of tolerance in patients who received the infusion of morphine.

\section{Introduction}

The effective relief of pain after operations is a major problem in clinical practice. ${ }^{1}$ After abdominal operations early postoperative analgesia is usually provided by opiates ${ }^{2}$ administered by intramuscular injection when the patient's tolerance to pain 